University of Montana

ScholarWorks at University of Montana

$12-2009$

\title{
Trade-Offs Between Predation Risk and Forage Differ Between Migrant Strategies in a Migratory Ungulate
}

Mark Hebblewhite

University of Montana - Missoula, mark.hebblewhite@umontana.edu

Evelyn Merrill

Follow this and additional works at: https://scholarworks.umt.edu/wildbio_pubs

Part of the Life Sciences Commons

Let us know how access to this document benefits you.

\section{Recommended Citation}

Hebblewhite, Mark and Merrill, Evelyn, "Trade-Offs Between Predation Risk and Forage Differ Between Migrant Strategies in a Migratory Ungulate" (2009). Wildlife Biology Faculty Publications. 23.

https://scholarworks.umt.edu/wildbio_pubs/23

This Article is brought to you for free and open access by the Wildlife Biology at ScholarWorks at University of Montana. It has been accepted for inclusion in Wildlife Biology Faculty Publications by an authorized administrator of ScholarWorks at University of Montana. For more information, please contact scholarworks@mso.umt.edu. 


\title{
Trade-offs between predation risk and forage differ between migrant strategies in a migratory ungulate
}

\author{
Mark Hebblewhite ${ }^{1,2,3}$ and Evelyn H. Merrill ${ }^{2}$ \\ ${ }^{1}$ Wildlife Biology Program, Department of Ecosystem and Conservation Sciences, College of Forestry and Conservation, University of \\ Montana, Missoula, Montana 59812 USA \\ ${ }^{2}$ Department of Biological Sciences, University of Alberta, Edmonton, Alberta T6G 2 E9 Canada
}

\begin{abstract}
Trade-offs between predation risk and forage fundamentally drive resource selection by animals. Among migratory ungulates, trade-offs can occur at large spatial scales through migration, which allows an "escape" from predation, but trade-offs can also occur at finer spatial scales. Previous authors suggest that ungulates will avoid predation risk at the largest scale, although few studies have examined multi-scale trade-offs to test for the relative benefits of risk avoidance across scales. Building on previously developed spatial models of forage and wolf predation risk, we tested for trade-offs at the broad landscape scale and at a finer, within-home-range scale for migratory and non-migratory resident elk (Cervus elaphus) during summer in the Canadian Rockies in Banff National Park (BNP) and adjacent Alberta, Canada. Migration reduced exposure to wolf predation risk by $70 \%$ relative to residents at the landscape scale; at the fine scale, migrants used areas that were, on average, $6 \%$ higher in forage digestibility. In contrast, by forgoing migration, resident elk were exposed to higher predation risk, but they reduced predation risk at fine scales to only $15 \%$ higher than migrants by using areas close to human activity, which wolves avoided. Thus, residents paid for trying to avoid predation risk with lower forage quality. Residents may have been able to compensate, however, by using areas of abundant forage close to human activity where they may have been able to forage more selectively while avoiding predation risk. Human activity effectively decoupled the positive correlation between high forage quality and wolf predation, providing an effective alternate strategy for residents, similar to recent findings in other systems. Although ungulates appear capable of balancing risk and forage at different spatial scales, risk avoidance at large landscape scales may be more effective in the absence of humancaused refugia from predation.
\end{abstract}

Key words: Banff National Park, Alberta, Canada; Cervus elaphus; elk; habitat selection; migration; partial migration; refugia; risk-forage trade-off; wolf predation.

\section{INTRODUCTION}

Ungulates consume plants and are consumed by predators, and must therefore adopt behavioral strategies to trade off access to forage against the risk of predation (Festa-Bianchet 1988, Fryxell et al. 1988, Houston et al. 1993). Theoretical advances from smallscale experiments on how animals make these trade-offs (Gilliam and Fraser 1987) provide limited understanding for real environments because trade-offs can occur across a range of spatiotemporal scales (Lima and Zollner 1996, Lima 2002, Dussault et al. 2005). For example, ungulate migration is a large-scale strategy that can allow ungulates to "escape" predation by moving beyond the ranges of non-migratory predators

Manuscript received 12 November 2008; revised 5 March 2009; accepted 20 March 2009. Corresponding Editor: T. J. Valone.

${ }^{3}$ Present address: University of Montana, Wildlife Biology Program, Department of Ecosystem and Conservation Sciences, College of Forestry and Conservation, 32 Campus Drive, Missoula, Montana 59812 USA.

E-mail: mark.hebblewhite@umontana.edu
(Fryxell et al. 1988, Rettie and Messier 2000). Rettie and Messier (2000) argue that avoidance of predation will be the most common at large spatial scales. Yet complete escape from predation, even by migrating across broad spatial scales, will be uncommon, in part, because migration itself is often risky (Lank et al. 2003, Schmaljohann and Dierschke 2005) and because not all ungulates are migratory. Furthermore, ungulates can avoid predators at fine spatial scales by exploiting heterogeneity in predator distribution (i.e., refugia), temporally avoiding predator activity, or by reducing vulnerability through behavioral mechanisms (Hamilton 1971, Hernandez and Laundre 2005, Gude et al. 2006, Poole et al. 2007, Winnie and Creel 2007). Understanding how herbivores like ungulates trade off between risk and forage across spatial scales is therefore an important question in ecology. Although ungulates will certainly make risk-forage trade-offs across scales, there may be greater relative benefits at one scale compared to another. For example, risk avoidance at the largest spatial scales may "free" ungulates to focus on forage at smaller spatial scales, where there might be a greater 
direct cost to foraging of avoiding predation risk (Houston et al. 1993, Brown and Kotler 2004).

Few studies have directly addressed multi-scale tradeoffs between forage selection and predator avoidance, however. Instead, previous studies have evaluated the benefits to foraging or predation avoidance independently (Bergerud et al. 1990, Mysterud et al. 2001, Hebblewhite and Merrill 2007, 2008), and most often used proxies for forage or predation risk, such as snow depth, land cover types, or hiding cover (Mysterud et al. 1999, Johnson et al. 2002, Pierce et al. 2004, Dussault et al. 2005). Progress in understanding what Lima and Zollner (1996) call the "behavioral ecology of ecological landscapes" or Brown and Kotler's (2004) "landscape of fear" has been hampered by the challenge of quantifying risk and forage at realistically large enough scales. Experimental approaches such as giving-up densities (Brown and Kotler 2004), while promising, need to be scaled up to large landscapes to understand the consequences of risk-forage trade-offs (Lima and Zollner 1996, Schmitz 2005). Recent advances in the ability to measure forage availability at landscape scales through remote sensing (Pettorelli et al. 2005), and to spatially model predation risk (Kristan and Boarman 2003, Hebblewhite et al. 2005, Hebblewhite and Merrill 2007,2008 ) provide new opportunities to address riskforage trade-offs for ungulates across scales relevant to ecosystem management and species conservation. Spatial variation in predation risk and forage will yield a continuum from low risk and low forage to areas with high risk and high forage, and ungulates may be able to trade off within or between spatial scales in their behavioral strategies to avoid predation while gaining access to forage.

In this paper we test for trade-offs at multiple scales in selection between herbaceous forage biomass (hereafter forage) and wolf predation risk (hereafter risk) for a partially migratory elk (Cervus elaphus) population in the Canadian Rockies. Partial migration is classically defined where some individual elk migrate and others do not (Kaitala et al. 1993). We test whether avoidance of risk at a larger scale "frees" elk from risk-forage tradeoffs at finer scales using resource selection functions (RSF) based on telemetry data (Manly et al. 2002). RSFs relate the probability of selection of a resource unit to covariates such as risk and forage, and have been successful at linking fitness to the consequences of habitat selection in red deer (McLoughlin et al. 2006). Comparing resource selection and exposure between migratory and non-migratory (resident) elk provides a strong comparative design to ask how different migratory strategies make risk-forage trade-offs at different spatial scales. We evaluate the effect of resource selection at the home range (landscape-scale selection) and within-summer-home-range (within-home-range scale selection) scales to determine the effects on exposure to predation risk and forage quality. For migrants, if the hypothesis that migration "frees" ungulates to select forage at finer spatial scales were true, we expected that selection for forage should stay constant and not depend on predation risk (no trade-off, or interaction between risk and forage). In contrast, we expected resident resource selection to be governed by an interaction of forage and predation at the withinhome-range scale, indicating that their foraging strategy changed in areas of both high forage and predation (Pulliam 1989, Houston et al. 1993). Despite the hypothesized benefits of migration, resident elk were increasing (Hebblewhite et al. 2006); other work has suggested that this may occur because human activity can provide a fine-scale refuge from predation (e.g., Berger 2007). We tested this hypothesis by examining forage-risk correlations for migrants and residents close to and far from human activity. If wolves avoid humans (Hebblewhite and Merrill 2008), then we would expect a weaker correlation between risk and forage near human activity.

\section{Methods}

The study area was $\sim 7000 \mathrm{~km}^{2}$ of the Canadian Rockies in Banff National Park (BNP) and adjacent Alberta provincial lands, Canada. Both migrant and resident elk used the same winter range (and hence forage and risk), so we focused here only on the summer migratory period. Wolves were the main predator (Hebblewhite 2006) of a partially migratory elk population that migrated to summer ranges in BNP and wintered on the $\mathrm{Ya} \mathrm{Ha}$ Tinda (YHT) winter range outside of BNP (Hebblewhite et al. 2006). Human activity was concentrated on the YHT outside of BNP (Hebblewhite and Merrill 2008). Elk were captured using two corral traps $(n=129)$ and helicopter netgunning $(n=15)$ during winters 2002-2004 under approved animal capture protocols. For this paper, we used data from 109 adult female elk outfitted with 104 VHF and 27 GPS (Global Positioning Collars; some elk wore both) collars (LOTEK Ltd., Newmarket, Ontario, Canada) during the summer migratory period (1 June30 September; Hebblewhite et al. 2006) from 2002 to 2004. Of the collared sample, 67 were migrants and 44 residents. We collected VHF locations for collared elk from the air weekly, or daily from the ground, and only included VHF-collared elk with $>10$ locations/month. GPS data were screened to a consistent 2-h relocation schedule. Both location error (GPS collar error $=34 \mathrm{~m}$, VHF collar error $=218 \mathrm{~m})$ and fix-rate bias $(<10 \%)$ were low enough to not influence RSF models (Hebblewhite et al. 2007, 2008). See Hebblewhite et al. (2006) for more detailed information about the study area climate and vegetation details.

\section{Multi-scale trade-offs between forage and predation risk}

We evaluated elk resource selection for forage, predation, and their interaction at two spatial scales during summer (see Plate 1). At the landscape scale, availability of forage and predation was compared 
between migrant and resident summer ranges. Within summer home ranges, we evaluated trade-offs between forage and predation using RSFs (Manly et al. 2002). We evaluated the consequences of these resource selection strategies by comparing migrant and resident summer range exposure to risk and forage biomass and digestibility, based on estimates derived from previous research (Hebblewhite et al. 2008).

Forage biomass model.-During summer, what matters most for ungulates is not necessarily the amount of forage biomass, but its quality or digestibility, because ungulates must trade off between forage quality and quantity (Fryxell 1991, Wilmshurst et al. 1995). Previously, we showed that digestibility declined nonlinearly with increasing forage biomass $\left(r^{2}=0.36\right)$. Thus, selection by elk for maximum forage biomass would indicate avoidance of high-quality forage, whereas selection for intermediate or lower forage biomass would indicate selection for high-quality forage (Fryxell 1991, Hebblewhite et al. 2008). We focused on herbaceous forage (forbs, graminoids) only, because forage quality for elk is driven by herbaceous, not shrubby, vegetation in summer (Hebblewhite et al. 2008).

The availability of herbaceous forage biomass to elk was modeled during 2002-2004 using a dynamic forage model in a Geographic Information System (GIS); full details are given in Hebblewhite et al. (2008). We used stratified-random sampling ( $n=983$ plots) to sample forage (dry mass $\mathrm{g} / \mathrm{m}^{2}$ of forbs and graminoids) at the peak of the growing season (4 August) across land cover strata. The peak of herbaceous forage biomass $\left(\mathrm{g} / \mathrm{m}^{2}\right)$ was spatially mapped at a $30-\mathrm{m}^{2}$ pixel resolution using the best predictive general linear models (GLM) of spatial covariates. Next, forage growth was spatially modeled over the growing season from the start (8 May) to the end (15 October) in 16-day "maps" using the Normalized Difference Vegetation Index (NDVI) at a 250-m pixel size from MODIS satellites (Huete et al. 2002, Pettorelli et al. 2005) in open habitat, and in plots ( $n=30$ ) sampled $\sim 3.5$ times/season in closed habitat. There was a strong relationship between ground biomass, NDVI, and spatial covariates (elevation) that resulted in a strong predictive spatial model for forage biomass ( $r^{2}=0.75$; Hebblewhite et al. 2008). We used these relationships to develop a dynamic spatiotemporal model of forage biomass (at a $30-\mathrm{m}^{2}$ pixel size) adjusted by phenological dynamics across the study area (at a MODIS pixel size of $250 \mathrm{~m}^{2}$ ). Therefore, for each elk telemetry location, we determined the predicted forage biomass availability in each 16-day MODIS interval. We interpret different exposures to forage biomass between migratory strategies in terms of percentage digestibility, using the previously developed negative relationship between forage biomass and forage quality measured by digestibility (Hebblewhite et al. 2008). All GIS analyses were done in ArcGIS 9.2 (ESRI 2002).
Wolf predation risk model.-We used a previously developed spatial model of wolf predation risk by combining the summer resource selection patterns of wolves with their spatial density (Hebblewhite and Merrill 2007, 2008). Summer resource selection by wolves was estimated using locations $(n=12521)$ from 15 GPS-collared wolves from all five wolf packs that overlapped the elk population from 2002 to 2004. Risk was modeled using mixed-effects RSFs allowing for pack-level heterogeneity in selection for human activity (Hebblewhite and Merrill 2008). We modeled risk separately for night and day because wolf selection for human activity varied temporally (Hebblewhite and Merrill 2007). Seasonal-temporal wolf RSFs were then combined with their spatial density estimated based on a larger sample of 30 wolves using kernel density estimators (KDE), weighted by wolf pack size, to model the total predation risk function for elk (Hebblewhite and Merrill 2007). The largest driver of differences in predation risk between resident and migrant elk was the spatial density of wolves, not wolf pack size or variation in resource selection (Hebblewhite and Merrill 2007). We validated our spatial predation risk model using an independent sample of 67 adult female elk killed by wolves: our total predation risk model was highly predictive of elk mortality locations (Pearson's $r=$ 0.97, $P<0.0005$; see Hebblewhite and Merrill 2007).

Risk-forage correlation.-A crucial condition for a observing a trade-off is a positive correlation between forage and predation such that there are few options to select for maximum forage quality while avoiding predation risk (Houston et al. 1993, Bowyer et al. 1998, Mitchell and Lima 2002). Without this correlation or condition, foragers can simply maximize forage and avoid predation simultaneously, and a trade-off is not required. In the case of ungulates in the summer, where forage quality is maximized at an intermediate forage biomass (Fryxell et al. 1988), risk should therefore peak at intermediate forage biomass. We tested the correlation structure between risk and forage quality using $n=$ 1000 random locations within elk home ranges using Pearson correlation coefficients.

\section{Landscape-scale selection}

An individual elk's decision to migrate reflects resource selection at the landscape level. To assess resource selection at this broad spatial scale, we compared availability of forage biomass and predation between migrant and resident summer ranges for all elk (e.g., 109 GPS- and VHF-collared elk). For each elk, we estimated one multi-annual $100 \%$ minimum convex polygon (MCP) summer range, and then summarized the summer range availability of predation risk within this $100 \%$ MCP. To test for differences in predation risk at this large scale, we contrasted elk exposure to the components of predation risk previously detailed here and in Hebblewhite and Merrill (2007). Forage biomass early in the growing season (16 May) and during the 
peak of the growing season (5 August) was averaged across the home range and compared between migrant and resident ranges using MANOVA (StataCorp 2003). Variables were then tested individually using a one-way ANOVA, correcting for multiple comparisons using the Bonferroni correction to evaluate the significance of the difference.

\section{Within-home-range scale selection}

The home-range RSF models were developed using GPS locations from 19 migrant and 8 residents during summer 2002-2004. We evaluated resource selection for forage biomass, predation, and their interaction using the use-available design of Manly et al. (2002) and assuming an exponential model (Johnson et al. 2006) in which year-specific risk and forage biomass covariates at used and random locations were contrasted to estimate

$$
\hat{w}(x)=\exp \left[\hat{\beta}_{1} F+\hat{\beta}_{2} P+\hat{\beta}_{3}(F \times P)\right]
$$

where $\hat{w}(x)$ is the relative probability of selection as a function of the coefficients $\hat{\beta}$ of forage biomass $(F)$, predation $(P)$, and their interaction $(F \times P)$ estimated from fixed-effects logistic regression (Manly et al. 2002) in Stata 8.0 (StataCorp 2003). Note that the trade-off implied by the interaction $F \times P$ is the key to testing whether elk were making trade-offs between risk and forage, because an interaction implies that selection for forage, for example, changes as a function of predation risk (Pulliam 1989). In the absence of an interaction, elk would continue to show the same selection pattern for forage, say, while predation risk changed, indicating that elk did not have to make a trade-off between forage and risk.

A random intercept was included for individual elk to control for heterogeneity in resource selection and unbalanced sampling designs using GLLAMM in Stata 8.0 (Skrondal and Rabe-Hesketh 2004, Gillies et al. 2006). The inclusion of a random intercept may change the coefficients, but is not included in Eq. 1 because it is a relative probability function (Gillies et al. 2006). We sampled availability of forage biomass and predation for each elk using 10 random points $/ \mathrm{km}^{2}$ within all $100 \%$ MCP summer home ranges. Because forage quality declines with increasing biomass, migrant elk would maximize forage quality by selecting intermediate or low forage biomass (Fryxell et al. 1988). In contrast, residents selected for maximum forage biomass (Hebblewhite et al. 2008). These two strategies were tested for in RSF models by including a linear and quadratic (intermediate) term for forage biomass in Eq. 1 (e.g., $\beta F$ $+\beta F^{2}$ ). We also tested linear, quadratic, and fractional polynomial (Hosmer and Lemeshow 2000) terms for predation. The top model from the all-inclusive simple candidate set of forage biomass, predation, their interaction, and so forth, was selected using $\mathrm{AIC}_{\mathrm{c}}$ where $n$ was considered the number of animals, not locations (Burnham and Anderson 1998). Predictive capacity of RSF models was assessed using $k$-folds cross validation within 10 equal-interval bins of available relative probabilities (Boyce et al. 2002).

\section{Consequences of migration strategies to elk}

To evaluate the consequences of the different migration strategies (i.e., resource selection strategies) for avoiding risk and maximizing forage, we assessed the exposure of all 109 elk to risk and report results of previous analyses for forage biomass and forage quality (from Hebblewhite et al. 2008). Exposure to predation risk $(Y)$ was estimated using a linear mixed-effects model with a random effect for each elk (Skrondal and Rabe-Hesketh 2004), a first-order autocorrelation term, and categorical variables for migratory status, the three summers of the study, and interactions between migrant status and year using XTREGAR in STATA 8.0 (Baltagi and Wu 1999, StataCorp 2003). We used the following model:

$$
\begin{aligned}
Y_{i t}= & \beta_{0}+\beta_{\mathrm{M}} X_{1 i}+\beta_{2} X_{2 i}+\cdots+\beta_{\mathrm{n}} X_{t i}+\beta_{\mathbf{M}} \mathbf{X}_{\mathbf{t}}+\gamma_{i} \\
& +\rho_{1} \varepsilon_{\mathrm{iVHF}}(\text { at } t-1)+\rho_{2} \varepsilon_{\mathrm{iGPS}}(\text { at } t-1)+\eta_{i t}
\end{aligned}
$$

where $Y_{i t}$ is the exposure to predation risk $(P)$ for elk $i=1$ during season $t, \beta_{\mathrm{M}}$ is the effect of migrant elk, $\beta_{2}, \ldots, \beta_{t}$ are the seasonal coefficients (spring 2002, and so forth), $\beta_{\mathbf{M}} \mathbf{X}_{\mathbf{t}}$ is the vector of migrant $\times$ summer interactions, $\gamma_{i}$ is the random effect of elk $i, \rho_{1} \varepsilon_{\mathrm{iVHF}}$ (at $t$ $-1)$ and $\rho_{2} \varepsilon_{\mathrm{iGPS}}($ at $t-1)$ are the first-order autocorrelation terms for GPS- and VHF-collared elk, respectively, and $\eta_{i t}$ is the random error. We modeled differences in autocorrelation in VHF and GPS data explicitly with the $\rho \varepsilon_{\mathrm{iGPS}}($ at $t-1)$ terms. XTREGAR is robust to unbalanced observations in both $i$ and $t$ and seasonal gaps in $t$ for $i$ (Baltagi and Wu 1999). The top model was selected from an all-inclusive set of models using AIC. Hebblewhite et al. (2008) used an identical linear mixed-effects model approach to test for the consequences of selection for forage biomass, is which reported here as forage biomass and percentage digestible dry matter for migrant and resident elk, based on quantity-quality regressions from this earlier study.

\section{Testing the refugia hypothesis for resident elk}

We tested the hypothesis that wolf avoidance of human activity at the YHT decoupled the positive forage-predation correlation (Hebblewhite and Merrill 2008), providing resident elk an opportunity to avoid fine-scale risk. We compared the correlation between forage biomass and predation greater than and less than the mean distance to human activity within resident elk summer ranges. The mean distance to human activity for resident summer ranges was $0.68 \mathrm{~km}$, compared to $2.9 \mathrm{~km}$ for migrant elk. If human activity reduced wolf risk for elk, then we expected the correlation or sign of the regression coefficient between risk and forage (and its quadratic) to be stronger farther from human activity than closer for resident elk, but not for migrant elk. Because forage quality declines with increasing biomass, 
TABLE 1. Landscape-level resource selection differences in total wolf predation risk and herbaceous forage biomass between migrant and resident elk (Cervus elaphus) summer ranges, Banff National Park, Canada, 2002-2004.

\begin{tabular}{|c|c|c|c|c|c|c|c|}
\hline \multirow[b]{2}{*}{ Covariate } & \multicolumn{2}{|c|}{ Migrant $(N=67)$} & \multicolumn{2}{|c|}{ Resident $(N=44)$} & \multicolumn{3}{|c|}{ Univariate ANOVA } \\
\hline & Mean & $\mathrm{SD}$ & Mean & $\mathrm{SD}$ & $F_{1,109}$ & $P$ & $r^{2}$ \\
\hline Total wolf risk $\dagger$ & 0.037 & 0.036 & 0.129 & 0.065 & 112.8 & $<0.0005$ & 0.46 \\
\hline Forage biomass, 16 May $\left(\mathrm{g} / \mathrm{m}^{2}\right)$ & 4.22 & $\begin{array}{l}0.050 \\
3.17\end{array}$ & 8.34 & 4.96 & $\begin{array}{r}112.8 \\
27.9\end{array}$ & $<0.00005$ & $\begin{array}{l}0.40 \\
0.21\end{array}$ \\
\hline Forage biomass, 5 Aug $\left(\mathrm{g} / \mathrm{m}^{2}\right)$ & 10.63 & 4.96 & 17.11 & 7.17 & 31.15 & $<0.00005$ & 0.23 \\
\hline
\end{tabular}

Notes: Sample sizes $(N)$ are the number of elk per study population. Means are the average availability within the $100 \%$ summer range of (1) the probability of predation by wolves and (2) forage biomass in May and August. Univariate ANOVA results are given for each covariate, with the $P$ value evaluated at an experiment-wise error rate adjusting for multiple comparisons of $P=$ $0.05 / 3=0.017$.

$\uparrow$ Probability described in Hebblewhite and Merrill (2007).

however, a positive correlation between forage biomass and risk might not indicate a trade-off. Considering that forage quality declines with forage biomass, a quadratic nonlinear correlation between forage biomass and risk implies a positive forage-quality-risk correlation. Thus, we also tested for quadratic relationship between risk and forage biomass using multiple linear regression. We compared correlation or regression coefficients using the $z$ test for homogeneity (StataCorp 2003).

\section{RESUlTS \\ Landscape-scale selection}

At the landscape scale, resident and migrant summer ranges differed for all three covariates (MANOVA $F_{3,102}=30.31, P<0.0005$; Wilks' $\left.\lambda=0.3455\right)$, even after adjusting for multiple comparisons (Table 1). Both spring (May) and peak forage biomass (August) on migrant ranges was $30-40 \%$ lower than on resident ranges (Table 1), reflecting delayed phenology and, hence, higher forage quality on migrant ranges at the landscape scale (Hebblewhite et al. 2008). Total predation risk on migrant ranges was $70 \%$ lower than on resident summer ranges at this landscape scale (Table $1)$.

\section{Within-home-range-scale selection}

We used 2762 VHF and 44320 GPS locations from the 109 elk during summers 2002-2004 to develop RSFs. Forage biomass was positively correlated with predation risk at random locations throughout within elk summer ranges $(r=0.37, P<0.0005)$, but the correlation was weaker than collinearity guidelines $(r=0.5-0.70$; Hosmer and Lemeshow 2000). There was low model selection uncertainty for both the top migrant and resident RSF models; the second-ranked migrant and resident models both had low support (AIC weight $=$ 0.14 and 0.07 , respectively; Table 2). Thus, we interpreted only the top model here. $K$-folds cross validation for five randomly selected partitions of the migrant and resident data had mean Spearman rank correlations of $0.86+0.012$ (migrant model) and $0.94+0.023$ (resident model) between observed and expected probabilities of use, indicating high predictive accuracy (Table 3).

Migrant elk selected for intermediate levels of forage biomass regardless of the level of predation risk, with no trade-off or interaction between forage and predation risk. Thus, as risk of predation increased, migrants reduced only the strength of selection for intermediate forage biomass (Table 2, Fig. 1). In contrast, the top model for resident elk had similar structure to that of migrant elk, with selection for maximum forage, but also a strong negative interaction between predation and forage (Table 2). Under low predation, residents selected intermediate forage biomass exactly the same as migrants (Table 2). However, given the interaction term, as predation risk increased, residents changed their forage selection, switching to maximize forage biomass (Fig. 1a).

\section{Consequences of migration strategies to elk}

We report consequences of migration from a topdown (predation) and bottom-up (forage quality) perspective at the within-home-range scale. From the top mixed-effects model (XTREGAR, Wald $\chi^{2}=14.85$, $P<0.007, R^{2}$ (overall $)=0.20, R^{2}($ within-elk $)=0.30$, $R^{2}$ (between-elk) $=0.03, \rho_{1} \varepsilon_{\mathrm{iVHF}}($ at $t-1)=0.14$, $\rho_{2} \varepsilon_{\mathrm{iGPS}}($ at $\left.t-1)=0.58\right)$, predation risk differed between all three years $(P=0.02)$ but between migratory

TABLE 2. Top resource selection functions (RSF) models (indicated by bold $\Delta$ AIC values) for within-summer-range selection for forage $(F)$, predation $(P)$, and their interaction $(F \times P)$ for migrant and resident elk in the eastern slopes of Banff National Park, $2002-2004$

\begin{tabular}{|c|c|c|c|c|c|c|c|}
\hline \multirow[b]{2}{*}{ Model } & \multirow[b]{2}{*}{$k$} & \multicolumn{3}{|c|}{ Migrants } & \multicolumn{3}{|c|}{ Residents } \\
\hline & & LL & $\Delta \mathrm{AIC}$ & $w$ & LL & $\Delta \mathrm{AIC}$ & $w$ \\
\hline $\begin{array}{l}\text { 1) } F+F^{2}+P \\
\text { 2) } F+F^{2}+P+(F \times \mathrm{P})\end{array}$ & $\begin{array}{l}4 \\
5\end{array}$ & $\begin{array}{l}-26095 \\
-26093\end{array}$ & $\begin{array}{l}\mathbf{0 . 0} \\
3.7\end{array}$ & $\begin{array}{l}0.86 \\
0.14\end{array}$ & $\begin{array}{l}-13356 \\
-13351\end{array}$ & $\begin{array}{l}5.3 \\
\mathbf{0 . 0}\end{array}$ & $\begin{array}{l}0.07 \\
0.93\end{array}$ \\
\hline
\end{tabular}

Notes: Abbreviations are: $k$, the number of parameters; LL, log likelihood; $\Delta$ AIC, difference from the model with the lowest Akaike information criterion value; and $w$, AIC weight for the top model (see Burnham and Anderson 1998). 
TABLE 3. Top model structure and diagnostics for migrant and resident summer range RSF trade-off models between forage and risk of predation.

\begin{tabular}{lccccccc}
\hline \hline \multirow{2}{*}{$\begin{array}{c}\text { Elk } \\
\text { population }\end{array}$} & Pseudo $R^{2}$ & $n_{(0,1)}$ & $k$-folds $r_{\mathrm{S}}$ & Forage $(F)$ & Predation risk $(P)$ & $F^{2}$ & $F \times P$ \\
\hline Migrant & 0.11 & 17354,18625 & 0.867 & $0.064 \pm 0.001$ & $-1.671 \pm 0.122$ & $-0.0004 \pm 1.06 \times 10^{-5}$ & \\
Resident & 0.28 & 8736,26256 & 0.943 & $0.074 \pm 0.001$ & $1.816 \pm 0.217$ & $-0.0003 \pm 1.29 \times 10^{-5}$ & $-0.012 \pm 0.004$ \\
\hline
\end{tabular}

Notes: The number of available locations used in logistic regression is $n(0)$, and the number of used telemetry locations is $n(1)$. The $k$-folds cross validation evaluates five partitions of each data set, revealing good predictive accuracy (Spearman rank correlation) between observed and expected predictions from the RSF model. There was no significant interaction between forage and predation for the migrant population.

strategies only during summer $2003\left(\beta_{2003}=-0.02, \mathrm{SE}=\right.$ 0.005 ) (Fig. 2). Migration reduced risk exposure by $9 \%$ in $2002,29 \%$ in 2003 , and $8 \%$ in 2004 relative to resident elk. On average, risk exposure was reduced $15 \%$ by migration, but significantly so only in one of three summers (Fig. 2).

From a bottom-up forage perspective, migrant elk used areas with an average of $35 \mathrm{~g} / \mathrm{m}^{2}$ herbaceous biomass compared to residents that used areas with 71 g/m $\mathrm{m}^{2}$ (Hebblewhite et al. 2008: Fig. 8 and Appendix E). These differences in selection for forage biomass resulted in migrant elk being exposed to an average of $6 \%$ higher forage digestibility during summer migration, averaged over the three years of the study (Hebblewhite et al. 2008).

\section{Refugia hypothesis for resident elk}

For resident elk living closer to human activity $(<0.68$ $\mathrm{km}$, the average distance to humans for resident elk) the strength of the forage biomass-predation correlation was weaker closer $(r=0.21, P<0.005)$ than it was farther away $(>0.68 \mathrm{~km})$ from human activity $(r=0.51$, $P<0.001)$, and these correlation coefficients were statistically different $(P<0.001)$. For migrant elk, there was no difference between the strength of the foragepredation correlation $(P=0.9)$ for migrant elk closer $(r=$ $0.43, P<0.001)$ or farther $(r=0.39, P<0.001)$ than human activity $(>2.9 \mathrm{~km})$. These correlations supported the predictions of the refugia hypothesis, confirming the prediction that high human activity repelled wolf predation risk, allowing residents to exploit reduced risk at this fine scale. Quadratic regression models between risk and forage did not significantly alter our interpretation because the relationship between risk and forage biomass was linear (M. Hebblewhite, unpublished data).

\section{DisCUSSION}

Elk that migrated reduced risk of predation at large spatial scales, which freed them from the need to make finer-scale trade-offs between risk and forage, consistent with predictions of previous studies of migratory ungulates (Fryxell et al. 1988, Bergerud et al. 1990, Mysterud et al. 2001). At the fine scale, migrants were "free" to focus on obtaining the highest diet quality by selecting areas of intermediate forage biomass. Migrant elk reduced predation risk $70 \%$ compared to resident elk by moving farther from wolf denning areas (Hebblewhite and Merrill 2007). This supported our prediction that migrants would not have to make fine-scale tradeoffs between forage and predation because predation was overall very low on summer ranges. In contrast, resident elk had summer ranges much closer to wolf denning areas (Hebblewhite and Merrill 2007) and were exposed to higher predation risk, consistent with other systems with non-migratory ungulates (Fryxell et al. 1988, Bergerud et al. 1990). Despite considerably higher predation risk at large scales, however, resident elk adopted a fine-scale trade-off strategy, foraging in areas of the highest, rather than intermediate, forage biomass. This scale-dependent strategy reduced their fine-scale exposure to predation risk to only $15 \%$ higher than migrants (Hebblewhite and Merrill 2007), nearly equalizing risk between strategies at this fine scale. Despite the costs of foregoing migration, residents may have gained by avoiding risks associated with migration. Migration was the riskiest time of year for migrants, with wolf predation risk 1.7 times higher than in summer, and higher than for resident elk (Hebblewhite and Merrill 2007). Therefore, even with reduced risk on summer ranges at large scales, high predation risk during migration alone may reduce the benefits of migration in this system compared to not migrating. When considering an integrative view of risk across scales and migratory periods, migrants may have had equal predation risk when compared to residents. This is inconsistent with the majority of the literature, which predicts that residents suffer higher mortality where predators are non-migratory (Fryxell et al. 1988, Bergerud et al. 1990). This apparent paradox required further investigation to understand how residents were able to successfully trade off between risk and forage.

Given that forage biomass and predation are positively correlated, selection by residents under increasing predation risk for high forage abundance was puzzling because this strategy should have exposed elk to higher predation risk. However, the areas where forage biomass was high were spatially correlated with human activity, which wolves avoid, creating a predation refuge for elk (Hebblewhite and Merrill 2008). As a result, human activity decoupled the positive forage biomass-risk correlation required for a trade-off to occur. Thus, 

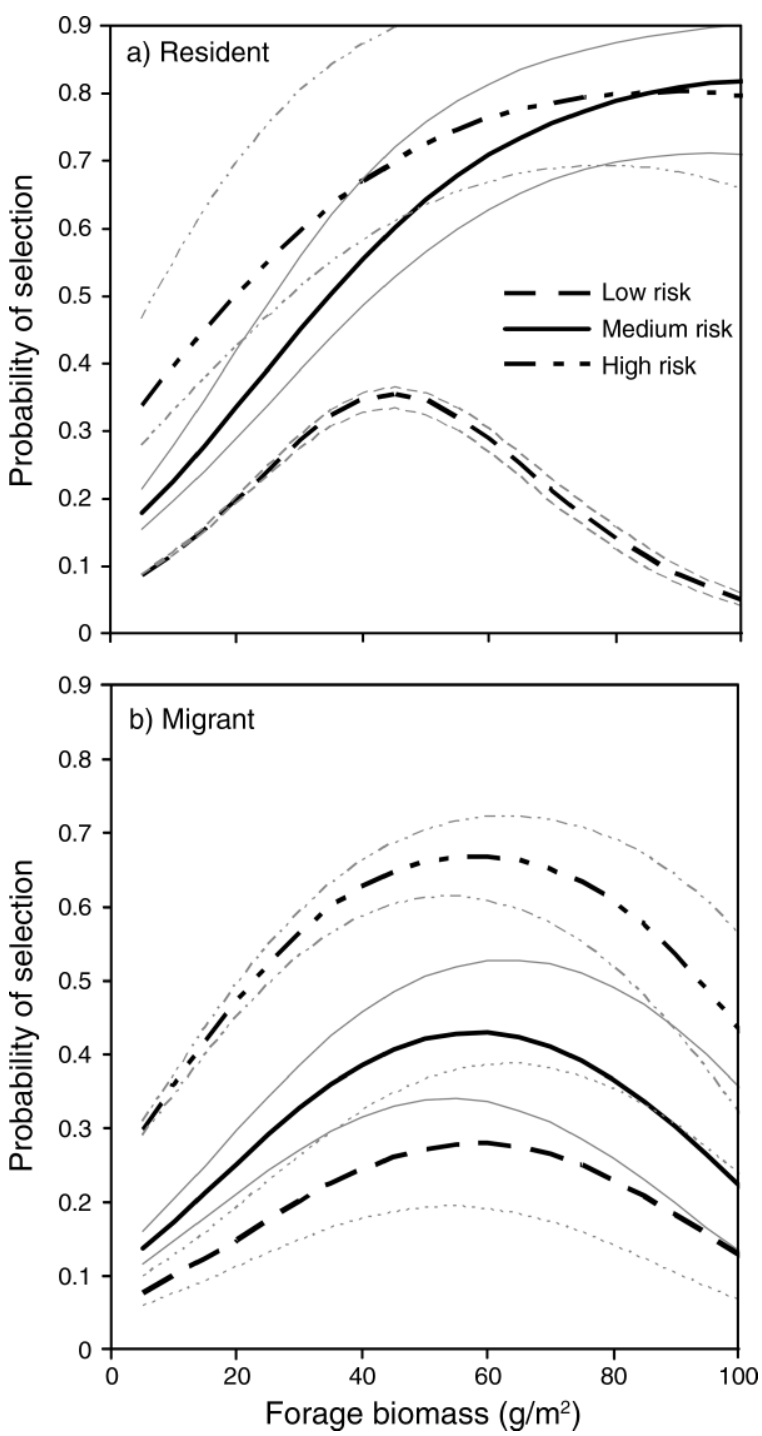

FIG. 1. Trade-offs in the relative probability of selection at the home-range scale from forage-predation trade-off RSF (resource selection functions) models for the Ya Ha Tinda elk (Cervus elaphus) population, Banff National Park, Alberta, Canada. Trade-offs are shown for (a) resident and (b) migrant elk for herbaceous forage biomass $(F)$ at low $(0.01)$, medium $(0.40)$, and high $(0.75)$ levels of relative wolf predation risk $(P)$ (range $0-1.00)$. Resident elk changed their behavior $(F \times P$ interaction) under increasing predation risk, selecting high forage biomass close to humans, whereas migrant elk did not experience a trade-off between risk and forage. For each risk level, 95\% confidence intervals (thin gray lines of corresponding types) on the predictions from RSF models are shown.

human activity created a low-risk-high-forage scenario that resident elk could exploit successfully. Similar anthropogenic refugia have been reported in a grizzly bear-moose system in Jackson Hole, Wyoming, USA (Berger 2007), and for wolves and elk nearby in Banff National Park (Hebblewhite et al. 2005). In circumstances where forage resources associated with anthropogenic refugia are too marginal, a resident population may not arise and the population may decline. Diversity of forage associated with overall high biomass at YHT (Hebblewhite 2006) may have promoted either strong selection at the scale of the food item to compensate for lower average quality of forage or large group sizes that contribute to reducing predation risk for residents (Hamilton 1971, Hebblewhite and Pletscher 2002, Hebblewhite 2006). However, as we show, where human activity has disrupted predator-prey dynamics, benefits of migration could be altered completely in favor of resident strategies (Hebblewhite et al. 2006).

Regardless of the success of a risk-forage trade-off by residents, from a forage quality perspective, migrants still benefited from migration (Albon and Langvatn 1992, Mysterud et al. 2001, Hebblewhite et al. 2008). Because of delayed phenology on migrant ranges, migrant exposure to forage had $\sim 5 \%$ higher digestibility than that of residents (Hebblewhite et al. 2008), and is consistent with the higher observed pregnancy rates and calf body mass of migrant elk (Hebblewhite 2006). In contrast, resident elk changed their forage selection strategies as risk increased. Under low risk, residents behaved similarly to migrants by selecting intermediate forage biomass. As risk increased, however, residents switched, selecting maximum forage biomass in areas that were less risky. This resulted in exposure to reduced forage quality for residents because of large-scale phenology gradients (Hebblewhite et al. 2008). Without the trade-off imposed by the avoidance of risky areas, resident elk still may have been exposed to a lower average forage quality than migrants because of the

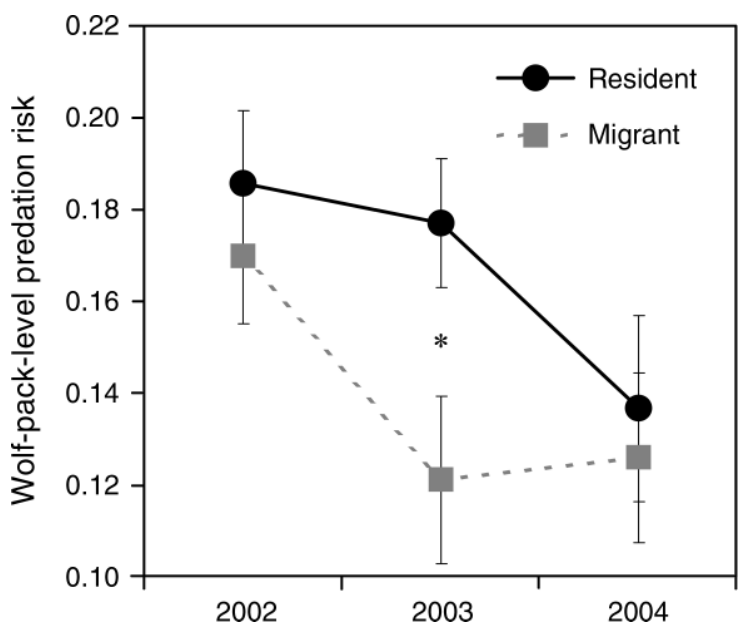

FIG. 2. Relative predation risk at the within-home-range scale for migrant (M) and resident (R) elk from the partially migratory Ya Ha Tinda elk herd, summers (1 June-30 September) 2002-2004. Predation risk averaged across individual elk is shown as mean \pm SE. An asterisk indicates a statistically significant $(P<0.05)$ difference between migrants and residents from a linear mixed-effects model accounting for individual elk and autocorrelation. See Consequences of migration strategies to elk for a description of predation risk. Reprinted with permission from Hebblewhite and Merrill (2008). 


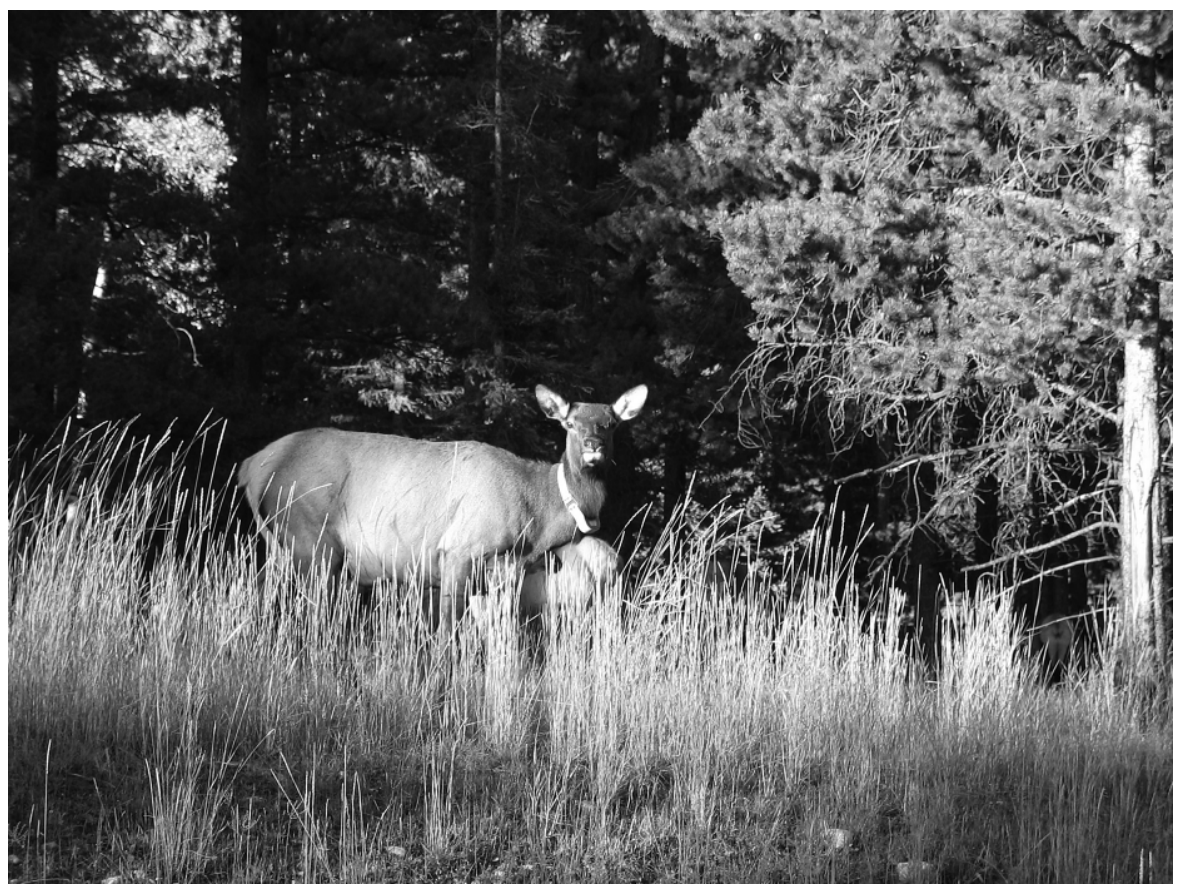

Plate 1. Migrant and resident elk make trade-offs between risk and forage at different spatial scales. This radio-collared resident elk remained on the winter range during summer, forgoing benefits of migration to high-forage-quality migratory summer ranges but avoided predation by selecting areas close to high human use where wolves avoided humans. Photo credit: M. Hebblewhite.

advanced phenology of low-elevation summer ranges. However, avoidance of risky areas undoubtedly exacerbated the overall poorer forage quality of residents, and probably contributed to why resident elk had lower pregnancy rates than migrants (resident $=0.83, n=63$, migrant $=0.90, n=78, P=0.02$ ) and reduced calf body mass $($ resident $=97.3 \mathrm{~kg}, n=11$, migrant $=117.9 \mathrm{~kg}, P<$ 0.0001; see Hebblewhite [2006] for details). Environmental stochasticity in forage quality may therefore leave residents especially vulnerable. The next step is to directly link resource selection and resulting forage and predation exposure by residents and migrants to demographic differences, the true measure of the consequences of resource selection.

From an evolutionary perspective, variation in predation risk and forage increases the likelihood of coexistence of migrant and resident strategies (Kaitala et al. 1993). Temporal variation in predation has important implications for relative population growth rates between strategies (Boyce 1991). In female elk, which may learn migratory behavior from their mothers, migratory strategy is often fixed, although some "switching" occurs. Over the life span ( $\sim 20$ years) of a female elk, migrants would therefore experience reduced predation. Resident elk, in contrast, still would be expected to have more years with high predation than migrants. How do residents persist, given these benefits to migration? The answer may lie in the covariation between predation and forage (Kaitala et al. 1993,
Boyce and Anderson 1999). For example, in 2004, resident elk exposure to predation risk was the lowest during the study when peak forage biomass on YHT was the highest (Hebblewhite et al. 2008). High forage biomass may have allowed residents to ameliorate lower forage quality by providing more choices at the bite level, and lower predation risk may have provided more flexibility to select for intermediate forage. Because predation risk is low and forage quality higher already for migrants than residents, 2004 would therefore have been a relatively better year for the resident segment than the migratory segment of the YHT elk herd. Unfortunately, few other studies have examined the effects of environmental stochasticty on the demography of partially migratory ungulates. Nicholson et al. (1997) found that migrant mule deer suffered higher mortality than residents in low precipitation years, but migrants had lower mortality in high precipitation (and hence forage) years. Thus, environmental stochasticity in forage availability balanced resident and migrant demography over time in this population, and was the mechanism maintaining partial migration for mule deer. Further, spatial variation may also play a role in mediating relative fitness of strategies, especially if variation in spatial predation risk is likely to be higher than variation in forage (Valeix et al. 2009, Willems and Hill 2009). For example, in 2003, migrant elk exposure to predation risk was $25 \%$ higher compared to $9 \%$ and $8 \%$ in the other years, primarily because a wolf pack 
overlapping the resident elk home ranges moved their den $20 \mathrm{~km}$ to a different valley. Future research should investigate, perhaps in a modeling framework, the conditions under which spatiotemporal stochasticity would favor migrant or resident strategies.

Our results do not completely support the hypothesis of Rettie and Messier (2000) that ungulates avoid the most important limiting factors at the largest spatial scales, while focusing on secondary factors at finer scales. They showed that caribou avoided habitats with higher expected wolf predation risk at large scales, focusing on foraging factors at finer scales, and concluded wolf predation was the most important factor. We found that migrant elk avoided risk at the largest scale and selected intermediate forage at finer scales, in agreement with Rettie and Messier (2000). However, by simultaneously avoiding predation risk and selecting for maximum forage biomass at fine scales, residents did not make trade-offs between, but rather at both spatial scales. Importantly, it was human activity that decoupled the risk-forage correlation that allowed residents to make this trade-off, so in the absence of human activity, Rettie and Messier's (2000) hypothesis may be true. Because of human activity, the selection strategy that we observed in resident elk was similar to that of moose in Quebec, which selected for both forage and predation risk at one scale (Dussault et al. 2005). Indeed, Johnson et al. (2001) concluded that, given behavioral flexibility of ungulates, there might be no inherent advantages to selecting forage or risk at any particular scale. Therefore, consequences of hierarchical habitat selection by ungulates need to be evaluated from a demographic perspective, and the hypothesis that the most important limiting factors are reflected by measures of selection at the largest scale may not always be true.

\section{ACKNOWLEDGMENTS}

Funding was provided by the Alberta Conservation Association, Alberta Cooperative Conservation Research Unit, Alberta Enhanced Career Development, Alberta Sustainable Resource Development, the Andrew Stewart Memorial Prize and the Bill Shostak Wildlife Award at the University of Alberta, Canon National Parks Science Scholarship for the Americas (MH), Centre for Mathematical Biology, Alberta Conservation Association Challenge Grants, Foothills Model Forest, Foundation for North American Wild Sheep, Mountain Equipment Co-op Environment fund, NSERC-CRO grant \#261091-02, Parks Canada, Rocky Mountain Elk Foundation, Sundre Forest Products Limited, Weyerhauser Inc., and the Universities of Alberta and Montana. We thank the staff and biologists of the Ya Ha Tinda ranch, Parks Canada, and Alberta Fish and Wildlife. For animal capture services, we thank T. Shury and C. Wilson, T. Vandenbrink of Bighorn Helicopters, and M. Dupuis for safe fixed-wing telemetry monitoring. We thank the numerous field assistants for invaluable help during this study, especially C. Mueller, L. Thurston, H. Spaedtke, and H. Keta. Finally, we thank S. Boutin, C. Cassady-St.Clair, C. Gates, F. Messier, L. Morgantini, N. C. Stenseth, D. Simader, and C. White for reviews of past drafts of this manuscript. J. Brown and one anonymous reviewer provided very helpful comments. Animal capture and handling was conducted under University of Alberta permit number 35112 and Parks Canada and Alberta Fish and Wildlife permits.

\section{Literature Cited}

Albon, S. D., and R. Langvatn. 1992. Plant phenology and the benefits of migration in a temperate ungulate. Oikos 65:502513.

Baltagi, B. H., and P. X. Wu. 1999. Unequally spaced panel data regressions with $\mathrm{AR}(1)$ disturbances. Econometric Theory 15:814-823.

Berger, J. 2007. Fear, human shields, and the re-distribution of prey and predators in protected areas. Biology Letters 3:620623.

Bergerud, A. T., R. Ferguson, and H. E. Butler. 1990. Spring migration and dispersion of woodland caribou at calving. Animal Behaviour 39:360-368.

Bowyer, R. T., J. G. Kie, and V. Van Ballenberghe. 1998. Habitat selection by neonatal black-tailed deer: climate, forage, or risk of predation? Journal of Mammalogy 79:415425.

Boyce, M. S. 1991. Migratory behaviour and management of elk (Cervus elaphus). Applied Animal Behavior Science 29: 239-250.

Boyce, M. S., and E. M. Anderson. 1999. Evaluating the role of carnivores in the Greater Yellowstone Ecosystem. Pages 265284 in T. W. Clark, A. P. Curlee, S. C. Minta, and P. M. Kareiva, editors. Carnivores in ecosystems: The Yellowstone experience. Yale University Press, New Haven, Connecticut, USA.

Boyce, M. S., P. R. Vernier, S. E. Nielsen, and F. K. A. Schmiegelow. 2002. Evaluating resource selection functions. Ecological Modelling 157:281-300.

Brown, J. S., and B. P. Kotler. 2004. Hazardous duty pay and the foraging cost of predation. Ecology Letters 7:999-1014.

Burnham, K. P., and D. R. Anderson. 1998. Model selection and inference: a practical information-theoretic approach. Springer-Verlag, New York, New York, USA.

Dussault, C., J. P. Ouellet, R. Coutois, J. Huot, L. Breton, and H. Jolicoeur. 2005. Linking moose habitat selection to limiting factors. Ecography 28:1-10.

ESRI. 2002. ArcGIS 9.2. ESRI (Environmental Systems Research Institute), Redlands, California, USA.

Festa-Bianchet, M. 1988. Seasonal range selection in bighorn sheep: conflicts between forage quality, forage quantity, and predator avoidance. Oecologia 75:580-586.

Fryxell, J. M. 1991. Forage quality and aggregation by large herbivores. American Naturalist 138:478-498.

Fryxell, J. M., J. Greever, and A. R. E. Sinclair. 1988. Why are migratory ungulates so abundant? American Naturalist 131: 781-798.

Gilliam, J. F., and D. F. Fraser. 1987. Habitat selection under predation hazard: test of a model with foraging minnows. Ecology 68:1856-1862.

Gillies, C., M. Hebblewhite, S. E. Nielsen, M. Krawchuk, C. Aldridge, J. Frair, C. Stevens, D. J. Saher, and C. Jerde. 2006. Application of random effects to the study of resource selection by animals. Journal of Animal Ecology 75:887-898.

Gude, J. A., R. A. Garrott, J. J. Borkowski, and F. King. 2006. Prey risk allocation in a grazing ecosystem. Ecological Applications 16:285-298.

Hamilton, W. D. 1971. Geometry for the selfish herd. Journal of Theoretical Biology 31:295-311.

Hebblewhite, M. 2006. Linking predation risk and forage to ungulate population dynamics. Dissertation. University of Alberta, Edmonton, Alberta, Canada.

Hebblewhite, M., and E. H. Merrill. 2007. Multiscale wolf predation risk for elk: does migration reduce risk? Oecologia 152:377-387.

Hebblewhite, M., and E. H. Merrill. 2008. Modeling wildlifehuman relationships for social species with mixed-effects 
resource selection models. Journal of Applied Ecology 45: 834-844.

Hebblewhite, M., E. H. Merrill, and G. McDermid. 2008. A multi-scale test of the forage maturation hypothesis for a partially migratory montane elk population. Ecological Monographs 78:141-166.

Hebblewhite, M., E. H. Merrill, and T. E. McDonald. 2005. Spatial decomposition of predation risk using resource selection functions: an example in a wolf-elk system. Oikos 111:101-111.

Hebblewhite, M., E. H. Merrill, L. E. Morgantini, C. A. White, J. R. Allen, E. Bruns, L. Thurston, and T. E. Hurd. 2006. Is the migratory behavior of montane elk herds in peril? The case of Alberta's Ya Ha Tinda elk herd. Wildlife Society Bulletin 34:1280-1295.

Hebblewhite, M., M. Percy, and E. H. Merrill. 2007. Are all GPS collars created equal? Correcting habitat-induced bias using three brands in the Central Canadian Rockies. Journal of Wildlife Management 71:2026-2033.

Hebblewhite, M., and D. H. Pletscher. 2002. Effects of elk group size on predation by wolves. Canadian Journal of Zoology 80:800-809.

Hernandez, L., and J. W. Laundre. 2005. Foraging in the 'landscape of fear' and its implications for habitat use and diet quality of elk (Cervus elaphus) and bison (Bison bison). Wildlife Biology 11:215-220.

Hosmer, D. W., and S. Lemeshow. 2000. Applied logistic regression. John Wiley, New York, New York, USA.

Houston, A. E., J. M. McNamara, and J. M. C. Hutchinson. 1993. General results concerning the trade-off between gaining energy and avoiding predation. Philosophical Transactions of the Royal Society of London B 341:375-397.

Huete, A., K. Didan, T. Miura, E. P. Rodriguez, X. Gao, and L. G. Ferreira. 2002. Overview of the radiometric and biophysical performance of the MODIS vegetation indices. Remote Sensing and the Environment 83:195-213.

Johnson, C. J., S. E. Nielsen, E. H. Merrill, T. L. McDonald, and M. S. Boyce. 2006. Resource selection functions based on use-availability data: theoretical motivations and evaluations methods. Journal of Wildlife Management 70:347-357.

Johnson, C. J., K. L. Parker, and D. C. Heard. 2001. Foraging across a variable landscape: behavioural decisions made by woodland caribou at multiple spatial scales. Oecologia 127: $590-602$.

Johnson, C. J., K. L. Parker, D. C. Heard, and M. P. Gillingham. 2002. Movement parameters of ungulates and scale-specific responses to the environment. Journal of Animal Ecology 71:225-235.

Kaitala, A., V. Kaitala, and P. Lundberg. 1993. A theory of partial migration. American Naturalist 142:59-81.

Kristan, W. B., and W. I. Boarman. 2003. Spatial pattern of risk of Common Raven predation on desert tortoises. Ecology 84:2432-2443.

Lank, D. B., R. W. Butler, J. Ireland, and R. C. Ydenberg. 2003. Effects of predation danger on migration strategies of sandpipers. Oikos 103:303-320.

Lima, S. L. 2002. Putting predators back into behavioural predator-prey interactions. Trends in Ecology and Evolution 17:70-75.

Lima, S. L., and P. A. Zollner. 1996. Towards a behavioural ecology of ecological landscapes. Trends in Ecology and Evolution 11:131-135.

Manly, B. F. J., L. L. McDonald, D. L. Thomas, T. L. McDonald, and W. P. Erickson. 2002. Resource selection by animals: statistical analysis and design for field studies. Second edition. Kluwer, Boston, Massachusetts, USA.

McLoughlin, P. D., M. S. Boyce, T. Coulson, and T. CluttonBrock. 2006. Lifetime reproductive success and densitydependent, multi-variable resource selection. Proceedings of the Royal Society B 273:1449-1454.

Mitchell, W. A., and S. L. Lima. 2002. Predator-prey shell games: large-scale movement and its implications for decision making by prey. Oikos 99:249-259.

Mysterud, A., R. Langvatn, N. G. Yoccoz, and N. C. Stenseth. 2001. Plant phenology, migration and geographical variation in body weight of a large herbivore: the effect of a variable topography. Journal of Animal Ecology 70:915-923.

Mysterud, A., L. B. Lian, and D. O. Hjermann. 1999. Scaledependent trade-offs in foraging by European roe deer (Capreolus capreolus) during winter. Canadian Journal of Zoology 77:1486-1493.

Nicholson, M. C., R. T. Bowyer, and J. G. Kie. 1997. Habitat selection and survival of mule deer: tradeoffs associated with migration. Journal of Mammalogy 78:483-504.

Pettorelli, N., J. O. Vik, A. Mysterud, J.-M. Gaillard, C. J. Tucker, and N. C. Stenseth. 2005. Using the satellite-derived NDVI to assess ecological responses to environmental change. Trends in Ecology and Evolution 20:503-510.

Pierce, B. M., R. T. Bowyer, and V. C. Bleich. 2004. Habitat selection by mule deer: forage benefits or risk of predation? Journal of Wildlife Management 68:533-541.

Poole, K. G., R. Serrouya, and K. Stuart-Smith. 2007. Moose calving strategies in interior montane ecosystems. Journal of Mammalogy 88:139-150.

Pulliam, H. R. 1989. Individual behaviour and the procurement of essential resources. Pages 25-38 in J. Roughgarden, R. M. May, and S. A. Levin, editors. Perspectives in ecology. Princeton University Press, Princeton, New Jersey, USA.

Rettie, W. J., and F. Messier. 2000. Hierarchical habitat selection by woodland caribou: its relationship to limiting factors. Ecography 23:466-478.

Schmaljohann, H., and V. Dierschke. 2005. Optimal bird migration and predation risk: a field experiment with northern wheatears Oenanthe oenanthe. Journal of Animal Ecology 74:131-138.

Schmitz, O. J. 2005. Scaling from plot experiments to landscapes: studying grasshoppers to inform forest ecosystem management. Oecologia 145:225-234.

Skrondal, A., and S. Rabe-Hesketh. 2004. Generalized latent variable modeling: multilevel, longitudinal, and structural equation models. Chapman and Hall, New York, New York, USA.

StataCorp. 2003. Stata Statistical Software: Release 8.0. Stata Corporation, College Station, Texas, USA.

Valeix, M., A. J. Loveridge, S. Chamaille-Jammes, Z. Davidson, F. Murindagomo, H. Fritz, and D. W. Macdonald. 2009. Behavioral adjustments of African herbivores to predation risk by lions: spatiotemporal variations influence habitat use. Ecology 90:23-30.

Willems, E. P., and R. A. Hill. 2009. Predator-specific landscapes of fear and resource distribution: effects on spatial range use. Ecology 90:546-555.

Wilmshurst, J. F., J. M. Fryxell, and R. J. Hudson. 1995. Forage quality and patch choice by wapiti (Cervus elaphus). Behavioral Ecology 6:209-217.

Winnie, J., and S. Creel. 2007. Sex-specific behavioral responses of elk to spatial and temporal variation in the threat of wolf predation. Animal Behaviour 73:215-225. 